\title{
Does stable sitting influence upper limb function in children with cerebral palsy?
}

\author{
Kübra Seyhan, Mintaze Kerem-Günel \\ Department of Physiotherapy and Rehabilitation, Faculty of Health Sciences, Hacettepe University, Ankara, Turkey. \\ E-mail: kubra.seyhan@hacettepe.edu.tr \\ Received: 28th September 2017, Revised: 9th April 2018, 20th April 2018, Accepted: 21st April 2018
}

\begin{abstract}
SUMMARY: Seyhan K, Kerem-Günel M. Does stable sitting influence upper limb function in children with cerebral palsy? Turk J Pediatr 2019; 61: 79-84.

Bilateral spastic cerebral palsy (BSCP) patients frequently need to use various sitting devices for body control and function. The aim of this study was to investigate whether the use of a belt to position the pelvis in an adjustable chair would affect upper limb function in preschool children with BSCP. Fortyone children with BSCP [mean age $44 \pm 11$, range 18-60 months] classified according to the Gross Motor Function Classification System (GMFCS), as level III $(n=21)$ and level IV $(n=20)$ were fitted with a hip-positioning belt. Upper limb functions were assessed by Quality of Upper Extremity Skills Test (QUEST). The median scores of the following upper extremity functions increased significantly by wearing the hip positioning belt: dissociated movements, grasping, weight bearing and protective extension. The total QUEST score increased from $56.7( \pm 46.3)$ to $66.1( \pm 39.2)(\mathrm{p}<0.001)$. The portable and adaptable hip-positioning belt may be used in daily life to improve upper limb activity in preschool children with moderate to severe BSCP.
\end{abstract}

Key words: hip, belt, upper, cerebral palsy, function.

Cerebral Palsy (CP) comprises a group of permanent, non-progressive disorders of posture and movement. Daily living activities such as transferring, sitting and playing are restricted. ${ }^{1-3}$ Spasticity is the most common neurological symptom of CP, occurring in about $80 \%$ of children. ${ }^{4}$ Muscle tone is persistently increased in both upper and lower limbs in bilateral spastic cerebral palsy (BSCP), and sitting can be severely impaired due to spasticity and poor truncal control. ${ }^{1,2}$ Sitting signifies transfer of the weight to a supporting surface mainly by the pelvis and hip. Sitting position allows efficient use of upper extremities. ${ }^{6-8}$ Approximately $30-40 \%$ of children with CP, and $80 \%$ of children with moderate to severe CP use assistive sitting devices designed according to their neurodevelopmental level in order to improve functionality. ${ }^{9,10}$ Children with moderate to severe BSCP (levels III-IV according to the Gross Motor Function Classification System, GMFCS), remain in sitting position for long periods in daily life. ${ }^{11,12}$ These children have low tone in body muscles but high tone in extremity muscles, insufficient postural stabilization, posterior tilt in the pelvis, spinal misalignment, and asymmetrical weight transfer in sitting position, all likely to increase the risk of deformities in the lower extremities and spine. Children with moderate to severe BSCP tend to sit on their sacrum instead of the ischial tuberosity. They lean forward in order not to fall backwards and move the center of gravity anteriorly. ${ }^{13-15}$ The lack of corrective protective and balance reactions, relative inactivity, lack of body stabilization are problems impairing the activity of the upper extremities. ${ }^{16,17}$

The importance of sitting on activity resulted in the design of adaptive sitting devices. However, Ryan 18 in their review concluded there was insufficient evidence about the efficiency of adaptive seating on posture and upper extremity function. Clinical recommendation was impossible because of the heterogeneity of the samples and sitting devices, and the absence of appropriate outcome indicators. ${ }^{18}$ In another systematic review Chung et al. ${ }^{19}$ stated the need for classification systems for motor function in well-defined populations. 
The lack of evidence on the effect of sitting position in children with BSCP is remarkable. A sitting position, "functional sitting position" with the hips abducted, is often recommended to stabilize the hip joint and allow the use of the arms. ${ }^{20,21}$ Considering the physiological and functional perspectives, we hypothesized that if the hips were positioned symmetrically in flexion, abduction and external rotation with the aid of a pelvic belt in an adjustable chair, the shift of the pelvis would be blocked, the trunk would be supported and the upper extremity function ameliorated in children with BSCP.

\section{Material and Methods}

This was an observational study regarding the differences of upper extremity function between before and after application of the hip-positioning belt.

\section{Participants}

This study was conducted at the Department of Physiotherapy and Rehabilitation, in the Pediatric Physiotherapy Unit, Faculty of Health Sciences, Hacettepe University. The families participating in the study signed consent forms stating informed, voluntary participation.

The study included children

- 18-60 months old

- diagnosed with bilateral spastic CP

- in level III-IV according to the GMFCS

- who had not undergone botulinum toxin injection or surgery in the last 6 months

The study excluded children in case of

- visual and hearing problems

- inability to follow the instructions

- restlessness

The study was approved by the Clinical Research Ethics Committee of Hacettepe University (approval number: GO 14/134 -13).

\section{Measures}

The GMFCS is a reliable, valid and standard method for classifying gross motor function into five levels with emphasis on transfer, sitting and mobility ${ }^{22}$. It provides an estimation of the equipment or mobility aids the child may need.
Level I: walks without limitations. Level II: walks with limitation. Level III: sits independently or at most with limited external support; walks with a hand-held mobility device. Level IV: usually sits with support and uses powered mobility or manual wheelchair. Level $V$ : transported in a Manual Wheelchair. ${ }^{12}$ The Manual Ability Classification System (MACS) is a reliable and valid classification for manual ability in children with $\mathrm{CP}$, describes the use of the hands in daily activities. ${ }^{23}$ Its five levels are based on self-initiated ability and the need for assistance. Children in MACS Level I handle objects easily and successfully, Level II handle most objects but with somewhat reduced quality or speed, level III handle objects with difficulty, need help in activities, Level IV handle a limited selection of easily manageable objects in adapted situations, and children in level $V$ cannot handle objects, their ability being severely limited even for simple actions ${ }^{24}$. Upper extremity function was measured using the Quality of Upper Extremity Skills Test (QUEST) as the primary outcome measure in our study. The QUEST is a 34-item observational criterion-referenced test consisting of four subsections: dissociated movement, grasp, weight bearing, and protective extension. The scores are calculated for each section using a standardized percentage value and the average of the sections gives the total score. High scores indicate higher performance. QUEST has high reliability, internal consistency and intra/interrater concordance. ${ }^{25}$

\section{Procedure}

All assessments were performed by an experienced pediatric physiotherapist. Children were given the opportunity to become familiar to the evaluator, room, and adjustable chair. Demographic characteristics (age, weight, height) were recorded. Gross motor function level (GMFCS), manual ability level (MACS), and upper extremity skills (QUEST) were assessed at the first visit. The first QUEST was performed in sitting position on the chair without hip positioning belt.

After one week, the child was brought for the second QUEST administration that was repeated on the same chair with a pelvic belt to evaluate the effect of hip support on upper extremity function. 
Table I. Demographic Characteristics of Children.

\begin{tabular}{lc}
\hline Characteristics & $\mathrm{N}=41$ \\
\hline Mean age (SD) & $44(11)$ months \\
Male/ female, n (\%) & $20(48.8) / 21(51.2)$ \\
Weight & $13.3(3.0) \mathrm{kg}$ \\
Height & $91.9(11.5) \mathrm{cm}$ \\
Limb involvement (BSCP) & $\mathrm{n}(\%)$ \\
Diplegia & $19(46.3)$ \\
Quadripleqia & $22(53.7)$ \\
GMFCS & $\mathrm{n}(\%)$ \\
Level III & $21(51.2)$ \\
Level IV & $20(48.8)$ \\
MACS & $\mathrm{n}(\%)$ \\
Level I & $4(9.5)$ \\
Level II & $14(33.3)$ \\
Level III & $20(47.6)$ \\
Level IV & $3(7.1)$ \\
\hline
\end{tabular}
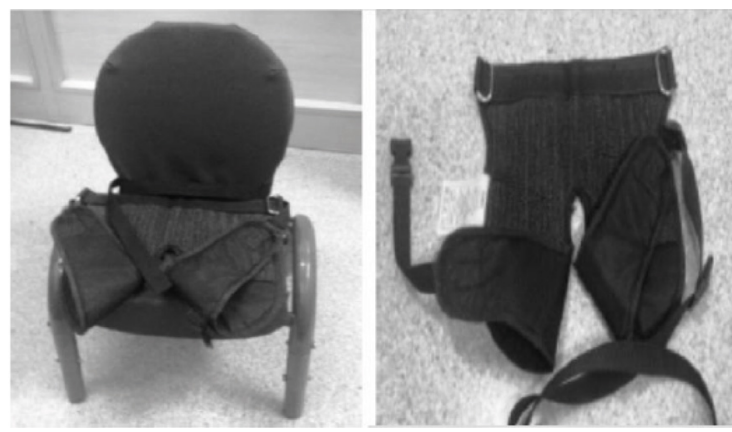

Fig. 1. The adaptive chair and hip positioning belt

adjusted to the height of the child.

\section{Statistical analysis}

A Windows-based SPSS 17.0 (IBM, USA) analysis program was used for the statistical analysis. The measurement data were indicated as the mean (X) and standard deviation (SD). The data indicated by numbers were evaluated as number (n) and percentage (\%). Wilcoxon signed rank test ${ }^{26}$. was used to assess differences between the upper extremity function QUEST scores in the unsupported sitting position (without the hip belt) and those in the supported sitting position (using the hip belt) with median values and interquartile range (IQR). Statistical significance was set at $p<0.05$. The size of changes effects of QUEST Total Score in groups were calculated with Cohen's d where sizes 0 to 0.2 is a small, 0.2-0.5 moderate, 0.5-0.8 large and more than 1.3 were taken as very large size of effect. ${ }^{27}$

the chair to stop the child from slipping. There was no armrest to assess the upper extremity movements and reactions. (Fig. 1).

Pelvic positioning belt: The belt is covered with soft fabric, adaptable to any chair, has two thick bands fixed by pulling toward the back of the chair, positioned between the legs in front of the cushion to prevent lumbosacral sitting, shifting forward. It places the hips in the abduction and external rotation position (Fig. 1). In addition, a desk adjusted to the height of the child was used while testing the upper extremities.

Position of the child: Hips were at approximately $90^{\circ}$ flexion, $10-20^{\circ}$ abduction and external rotation symmetrically with the back of child positioned fit to the chair. The desk was

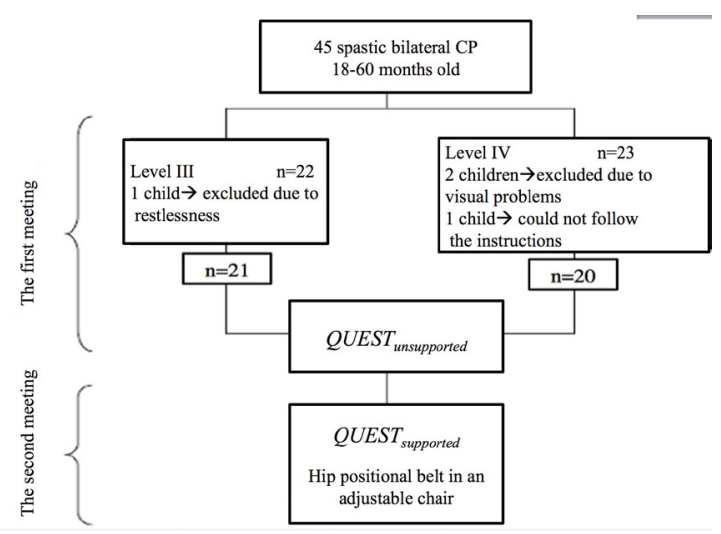

Fig. 2. The flow chart of the study 
Table II. The Changes of QUEST Subdivisions and Total Scores.

\begin{tabular}{llllllc}
\hline \multirow{2}{*}{ QUEST } & \multicolumn{2}{l}{ Unsupported $(\mathrm{n}=41)$} & \multicolumn{2}{l}{ Supported $(\mathrm{n}=41)$} \\
\cline { 2 - 7 } 1.Disassociated movement & Median (IQR) & $(25 \%-75 \%)$ & Median (IQR) & $(25 \%-75 \%)$ & $\mathrm{p}$ & $\mathrm{Z}$ \\
2. Grasp & $59.3(53.9)$ & $30.4-84.3$ & $71.8(34.3)$ & $53.1-87.5$ & $<0.001$ & -4.507 \\
3.Weight bearing & $37.0(59.2)$ & $3.7-62.9$ & $61.6(44.4)$ & $35.1-79.6$ & $<0.001$ & -5.192 \\
4.Protective extension & $61.1(50)$ & $33.3-83.3$ & $69.4(44.4)$ & $44.4-88.8$ & $<0.001$ & -3.900 \\
Total & $50(41.6)$ & $31.9-73.6$ & $61.1(41.6)$ & $36.1-77.7$ & $<0.001$ & -3.099 \\
\hline
\end{tabular}

QUEST: Quality of Upper Extremity Skills Test; IQR, inter quartile range; $Z$, Wilcoxon $Z$ value

\section{Results}

Forty-five children were evaluated, two children were excluded due to visual problems, one due to not follow the instructions and another due to restlessness (Fig. 2). Forty-one participants (20 males, 21 females; mean age: $44 \pm 11$ ) months; age range: 18-60 months) were included. Of them GMFCS levels of were 21 participants $(51.2 \%)$ were level III and 20 participants were $(48.8 \%)$ level IV. According to the MACS, 4 (9.5\%), 14 (33.3\%), 20 (47.6\%), and $3(7.1 \%)$ participants were level I, II, III, and IV, respectively. The other demographic characteristics are shown in Table I.

The QUEST subdivisions without and with wearing the hip positioning belt, were 59.37 (53.91) and $71.87(34.38)$ in disassociated movement; 37.03 (59.26) and 61.66 (44.45) in grasp functions; $61.11(50)$, and 69.44 (44.44) in weight bearing skills; and 50 (41.68) and 61.11 (41.66) in protective extension reactions of upper extremity and the median value of total QUEST score was 56.78 (46.31) without support and 66.11 (39.29) with hip positioning belt support. Changes in upper extremity function were significantly different and shown in Table II $(p<0.001)$.

When comparing the change in QUEST total scores for children in level III and IV with and without support, the effect was found to be large in both (Table III).

\section{Discussion}

The aim of this study was to investigate the effect of a hip-positioning belt on upper limb function in preschool children with BSCP level III-IV. We postulated that hip problems in the sitting position negatively affect the quality of sitting in children with $\mathrm{CP}$. The use of a pelvic belt that retains the hip and the legs in abduction and external rotation prevents lumbosacral sitting or shifting forward and ensures the selective movement in the upper extremities. We demonstrated significant differences in upper extremity functions statistically and clinically.

Himmelman et al. ${ }^{28}$ found that better gross motor function was related to better fine motor function in children with CP in 4-8 years. Heyrman et al. ${ }^{29}$ emphasized that better trunk control and better sitting balance was associated with better selective movements and reaching in 8-15 year old children with CP. Children with BSCP show poor static trunk control. Those $<6$ years old in level III sit on their own in any chair but may need trunk and pelvic support to increase hand functions. Children in Level IV require adaptive sitting arrangements to increase trunk control and hand functions. ${ }^{12}$ Miedaner et al. $^{30}$ evaluated the relationship between unsupported sitting versus supported sitting. They showed significant improvement in reaching and grasping function when seated in

Table III. The Effect Sizes of the QUEST Total Scores by GMFCS Levels.

\begin{tabular}{lcccc}
\hline \multicolumn{2}{l}{ GMFCS } & $\mathrm{D}$ & $\mathrm{SD}(\mathrm{D})$ & $\mathrm{ES}$ \\
\hline Level & III $(\mathrm{n}=21)$ & -8.88 & 6.42 & 1.38 \\
Level & IV $(\mathrm{n}=20)$ & -18.26 & 12.73 & 1.43 \\
\hline
\end{tabular}

$\mathrm{D}$, the average of difference; $\mathrm{SD}(\mathrm{D})$, standard deviation of the average of difference; $\mathrm{ES}$, effect size 
a fitted wheelchair. Mhyr et al. ${ }^{21,31}$ found that functional sitting position contributed the head, trunk, arm and hand function with adaptive device. On the other hand, Ekblom et al. ${ }^{32}$ found no significant effect of an abductor device used in sitting position on the activation of upper extremity muscle. In our study, we found supporting lower limbs and postural stability in the sitting position resulted in higher quality of reaching and grasping function.

Various authors evaluated the inclination of the sitting surface, sitting angles, pelvis position and postural management of children with BSCP. ${ }^{33,34}$ In our study both trunk support and pelvic positioning increased upper extremity performance. The heterogeneity of clinical types of $\mathrm{CP}$, wide range of age of children, presence of hypotonia and dyskinesia affect discrepancies between studies. Limitations in the current study include the subjectivity of QUEST, the lack of MACS after application of the pelvic positioning belt and absence of more detailed evaluation methods. However, the QUEST is an enjoyable and reproducible test for young children where upper extremity movements are viewed in a game setting.

Early intervention studies give better results when parallel to neurodevelopmental process. We can conclude that in preschool children with moderate to severe BSCP the use of a hip positional belt placing the pelvis in 90-degree flexion, abduction and external rotation results in functional sitting position and supports movements of upper extremities. This simple and light device can be adapted to any chair and may be used easily in physical therapy and rehabilitation interventions. Future studies with long-term use will shed light on its value in physiotherapy and rehabilitation approaches and daily life.

\section{Acknowledgments}

We would like to extend our thanks to our patients (Efe Arslan) father, Ibrahim Arslan for his help in designing and preparing the belt system.

\section{REFERENCES}

1. Rosenbaum P, Paneth N, Leviton A, et al. A report: the definition and classification of cerebral palsy April 2006. Dev Med Child Neurol Suppl 2007; 109: 8-14.
2. Anttila H, Autti-Rämö I, Suoranta J, Mäkelä M, Malmivaara A. Effectiveness of physical therapy interventions for children with cerebral palsy: a systematic review. BMC Pediatr 2008; 8:14.

3. Rethlefsen SA, Ryan DD, Kay RM. Classification systems in cerebral palsy. Orthop Clin of North Am 2010; 41: 457-467.

4. Pandyan AD, Gregoric M, Barnes MP, et al. Spasticity: Clinical perceptions, neurological realities and meaningful measurement. Disabil Rehabil 2005; 27: 2-6.

5. Krigger KW. Cerebral palsy: an overview. Am Fam Physician 2006; 73: 91-100.

6. Strobl WM. Seating. J Child Orthop 2013; 7: 395-399.

7. Kirkwood CA, Bardsley GI. Seating and positioning. In: Upper Motor Neurone Syndrome and Spasticity. $2^{\text {nd }}$ ed. Cambridge University Press. New York, USA. 2008: 99-113.

8. Brogren E, Hadders-Algraa M, Forssberg H. Postural control in sitting children with cerebral palsy. Neurosci Biobehav Rev 1998; 22: 591-596.

9. Rodby-Bousquet E, Hägglund G. Sitting and standing performance in a total population of children with cerebral palsy: a cross-sectional study. BMC Musculoskelet Disord 2010; 11: 131.

10. Østensjø S, Brogren E. Everyday functioning in young children with cerebral palsy: functional skills, caregiver assistance, and modifications of the environment. Dev Med Child Neurol 2003; 45: 603-612.

11. Cook AM, Polgar JM. Assistive technologies: Principles and practice ( $4^{\text {th }}$ ed) USA: Elsevier Health Sciences, 2014:1-16.

12. Palisano RJ, Rosenbaum P, Bartlett D, Livingston $M H$. Content validity of revised Gross Motor Function Classification System. Dev Med Child Neurol 2008; 50: 744-750.

13. Fulford G, Brown J. Position as a cause of deformity in children with cerebral palsy. Dev Med Child Neurol 1976; 18: 305-314.

14. Porter D, Michael S, Kirkwood C. Is there a relationship between preferred posture and positioning in early life and the direction of subsequent asymmetrical postural deformity in non ambulant people with cerebral palsy? Child Care Health Dev 2008; 34: 635-641.

15. Hulme JB, Gallacher K, Walsh J, Niesen S, Waldron D. Behavioral and postural changes observed with use of adaptive seating by clients with multiple handicaps. Phys Ther 1987; 67: 1060-1067.

16. Kluzik J, Fetters L, Coryell J. Quantification of Control: A Preliminary Study of Effects of Neurodevelopmental Treatment on Reaching in Children with Spastic Cerebral Palsy. Phys Ther 1990; 70: 65-76.

17. Nwaobi OM. Seating orientations and upper extremity function in children with cerebral palsy. Phys Ther 1987; 67: 1209-1212.

18. Ryan SE. An overview of systematic reviews of adaptive seating interventions for children with cerebral palsy: where do we go from here? Disabil Rehabil Assist Technol 2012; 7: 104-111. 
19. Chung J, Evans J, Lee C, et al. Effectiveness of adaptive seating on sitting posture and postural control in children with cerebral palsy. Pediatr Phys Ther 2008; 20: $303-317$

20. Mulcahy CM, Pountney TE, Nelham RL, et al. Adaptive Seating for Motor Handicap: Problems, a Solution, Assessment and Prescription. Br J Occup Ther 1988; 51: $347-352$

21. Myhr U, von Wendt L. Improvement of functional sitting position for children with cerebral palsy. Dev Med Child Neurol 1991; 33: 246-256.

22. Morris C, Bartlett D. Gross Motor Function Classification System: impact and utility. Dev Med Child Neurol 2004; 46: 60-65.

23. Eliasson A-C, Krumlinde-Sundholm L, Rösblad B, et al. The Manual Ability Classification System (MACS) for children with cerebral palsy: scale development and evidence of validity and reliability. Dev Med Child Neurol 2006; 48: 549-554.

24. Akpinar P, Tezel CG, Eliasson A-C, Icagasioglu A. Reliability and cross-cultural validation of the Turkish version of Manual Ability Classification System (MACS) for children with cerebral palsy. Disabil Rehabil 2010; 32: 1910-1916.

25. Haga N, van der Heijden-Maessen HC, van Hoorn JF, Boonstra AM, Hadders-Algra M. Test-retest and interand intrareliability of the quality of the upper-extremity skills test in preschool-age children with cerebral palsy. Arch Phys Med Rehabil 2007; 88: 1686-1689.

26. Gibbons JD, Chakraborti S. Nonparametric statistical inference. In: International Encyclopedia of Statistical Science. Berlin: Springer, 2011: 977-979.
27. Sullivan GM, Feinn R. Using Effect Size-or Why the P Value Is Not Enough. J Grad Med Educ 2012; 4: $279-282$

28. Himmelmann K, Beckung E, Hagberg G, Uvebrant P. Gross and fine motor function and accompanying impairments in cerebral palsy. Dev Med Child Neurol 2006; 48: 417-423.

29. Heyrman L, Molenaers G, Desloovere K, et al. A clinical tool to measure trunk control in children with cerebral palsy: the Trunk Control Measurement Scale. Res Dev Disabil 2011; 32: 2624-2635.

30. Miedaner J, Finuf L. Effects of adaptive positioning on psychological test scores for preschool children with cerebral palsy. Pediatr Phys Ther 1993; 5: 177-182.

31. Myhr U, Wendt L, Norrlin S, Radell U. Five-year follow-up of functional sitting position in children with cerebral palsy. Dev Med Child Neurol 1995; 37: 587-596.

32. Ekblom B, Myhr U. Effects of the hip abduction orthosis on muscle activity in children with Cerebral Palsy. Physiother Theory Prac 2002; 18: 55-63.

33. Macias-Merlo L, Bagur-Calafat C, Girabent-Farrés $M$, Stuberg W. Effects of the standing program with hip abduction on hip acetabular development in children with spastic diplegia cerebral palsy. Disabil Rehabil 2016; 38: 1075-1081.

34. Sahinoğlu D, Coskun G, Bek N. Effects of different seating equipment on postural control and upper extremity function in children with cerebral palsy. Prosthet Orthot Int 2017; 41:85-94. 